\title{
Gene Expression in Chronic High Altitude Diseases
}

\author{
Fabiola León-Velarde and Olga Mejía
}

\begin{abstract}
Léon-Velarde, Fabiola, and Olga Mejía. Gene expression in chronic high altitude diseases. High Alt. Med. Biol. 9:130-139, 2008. - Chronic mountain sickness (CMS) and high altitude pulmonary hypertension (HAPH) have been well described in different mountainous regions of the world as chronic high altitude (HA) diseases. This review briefly summarizes the available data from some genes known to be regulated by hypoxia-inducible factor 1 (HIF-1) and/or by hypoxia that have been studied in populations from these regions suffering from CMS and/or HAPH. Excessive erythrocytosis, caused by a lower oxygen saturation and hypoxic ventilatory response and/or ventilatory inefficiency, is the outstanding sign of CMS, and right ventricular enlargement, pulmonary hypertension, and remodeling of pulmonary arterioles are hallmarks of HAPH. Familial character and heritability studies have suggested that genetic factors could make a contribution to the pathogenesis of CMS and HAPH. Even though some alleles are more prevalent ( $G$ allele of eNOS polymorphism Glu298Asp in Sherpas and ACE I allele in HAPH Kyrgyz) or less prevalent (ACE D allele in HA Andeans) in the different high altitude populations, published data to date are insufficient for a rigorous test of any hypothesis regarding the implications of these gene polymorphims in CMS or HAPH.
\end{abstract}

Key words: eNOS gene; ACE gene; HIF-1; hypoxia; polymorphisms; chronic mountain sickness; high altitude pulmonary hypertension

\section{Introduction}

$\mathbf{H}$ IGH ALTITUDE LONGTIME residents are at risk of developing chronic mountain sickness (CMS, Monge's disease), a clinical syndrome that occurs in some natives or lifelong residents above $2500 \mathrm{~m}$. It is characterized by excessive erythrocytosis (EE) [females, hemoglobin $(\mathrm{Hb}): \mathrm{Hb} \geq 19 \mathrm{~g} / \mathrm{dL}$; males: $\mathrm{Hb} \geq 21 \mathrm{~g} / \mathrm{dl}$ ), severe hypoxemia, and in some cases moderate or severe pulmonary hypertension, which may evolve to cor pulmonale, leading to congestive heart failure. The clinical picture of CMS gradually disappears after descending to low altitude and reappears after returning to high altitude. High altitude pulmonary hypertension (HAPH) is a clinical condition, which occurs in children and adults resident above $2500 \mathrm{~m}$. It is characterized by a mean pulmonary artery pressure of $>30 \mathrm{mmHg}$ or a systolic pulmonary artery pressure of $>50 \mathrm{mmHg}$ measured at the altitude of residence, right ventricular hypertrophy, heart failure, moderate hypoxemia, and the absence of excessive erythrocytosis (León-Velarde et al., 2005). Even though CMS and HAPH represent separate manifestations of chronic hy- poxia, that is, stimulation of erythropoiesis and stimulation of pulmonary hypertension, respectively, in many patients with severe CMS, both manifestations are present simultaneously (Peñaloza and Sime, 1971; Peñaloza et al., 1971). Thus, patients with moderate CMS may have little or no elevation of pulmonary artery pressure or resistance beyond the normal increase at high altitude (Antezana et al., 1998; Vargas et al., 2003); alternatively, particularly in children and young adults, life-threatening HAPH may occur with little or no increase in $\mathrm{Hb}$ ( $\mathrm{Lin}$ and $\mathrm{Wu}, 1974$; Sui et al., 1988; Anand and $\mathrm{Wu}, 2004)$.

Alveolar hypoventilation and or ventilation/perfusion mismatch (Hurtado, 1942; Monge-M and Monge-C, 1966; Cruz et al., 1969; Ergueta et al., 1971; Ge, 1989; Vargas and Villena, 1992) play a central role in the physiopathology of CMS; this causes an overstimulation of erythropoiesis, leading to increased red cell mass and blood viscosity (Winslow and Monge, 1987). Hypoventilation and/or respiratory disorders could worsen with age, with obesity and chronic obstructive pulmonary disorders, with menopause, and during sleep in high altitude residents, further aggravating exces-

Laboratorio de Fisiología Comparada, Departamento de Ciencias Biológicas y Fisiológicas, Facultad de Ciencias y Filosofía, Universidad Peruana Cayetano Heredia, Lima, Perú. 
sive erythropoiesis (Sime et al., 1975; León-Velarde et al., 1993, 1994, 2001; Sun et al., 1996; Bernardi et al., 2003; Spicuzza et al., 2004).

Vasoconstriction is the cause of HAPH. A unique feature of pulmonary, as opposed to systemic, circulation is vasoconstriction observed at decreased levels of alveolar oxygen. When hypoxia is prolonged, increased muscularization occurs in the small pulmonary arteries of rats and humans, leading to increased pulmonary vascular resistance and sustained elevation of pulmonary arterial pressure (Arias Stella and Saldaña, 1963; Meyrick and Reid, 1980). The resulting pulmonary hypertension leads to right ventricular hypertrophy and in some individuals to "excessive" $\mathrm{HAPH}$ (Peñaloza and Sime et al., 1971).

In the Andean countries of South America, some 35 million people live above $2500 \mathrm{~m}$. Three of the capital cities in the Andes (La Paz, Bolivia; Bogotá, Colombia; Quito, Ecuador) are at high altitude. In Asia, 80 million people live above this altitude. For countries such as China and India, this number includes $\sim 2 \% 3 \%$ of the population respectively; for Afghanistan and Kyrgyzstan, 10\%; and for Nepal and Bhutan, between 35\% to $45 \%$ of $\sim 22$ and 2 million people, respectively. In Kyrghyztan, the high mountains of the Tien Shan and Pamir ranges account for $90 \%$ of its territory, and more than 200,000 people live above $3000 \mathrm{~m}$. In China alone, there are four high plateaus (Qinghai-Tibet, Inner Mongolia, Yun-Gui, and the Yellow Land Plateau), with a total population of nearly 40 million people. North America, Mexico and the western United States have relatively smaller ( $\sim 15$ million people), but increasing, high altitude populations (Niermeyer et al., 2001). It is estimated that between $5 \%$ and $10 \%$ of high altitude inhabitants may develop CMS or HAPH (León-Velarde et al., 2005). Large interindividual differences exist in the magnitude of the ventilatory response to hypoxia, the severity of erythremia, and the pulmonary pressure response to hypoxia, with some subjects demonstrating low ventilatory levels and/or exaggerated increases in pulmonary arterial pressure at high altitude. These features could imply a genetic susceptibility to CMS and HAPH; further, ethnic differences, familial clustering, and animal studies, which seem to show some genetic association with EE and the pulmonary pressure response to hypoxia, are suggestive of a genetic involvement in Monge's disease and in HAPH. In addition, quantitative genetic analysis has revealed, that the proportion of phenotypic variance in hemoglobin concentration attributable to genetic factors (i.e., the heritability of hemoglobin concentration) was $86 \%$ in the Tibetans and $87 \%$ in the Andeans (Beall et al., 1998). Although, these results indicate that genetic factors account for a large proportion of phenotypic variance in hemoglobin concentration in these populations, they do not identify the specific genetic factor underlying intrapopulation or interpopulation variation in response to altitude.

In general, very few genetic studies have been conducted on highland native populations. This paper reviews only those that attempt to provide a genetic explanation and understanding of CMS and HAPH. Even though much more research has been pursued in connection to the genetic basis of acute high altitude responses, this paper only deals with research that appears to be relevant for the purpose of this review.

\section{Candidate genes in CMS and HAPH-which genes?}

If there is a genetic involvement in CMS and $\mathrm{HAPH}$, the candidate genes could be key components within the respiratory and cardiovascular system sensitive to hypoxia, that is, genes known to be regulated by HIF and/or by hypoxia. An intermediate biochemical phenotype that reflects the HIF-related activation of transcription by hypoxia can be linked downward to common genetic variation within the HIF signaling pathway and upward to variation in integrative respiratory and cardiovascular responses to hypoxia.

\section{Hypoxia-inducible factor 1 (HIF-1)}

Hypoxia-inducible factor 1 was originally identified as a transcription factor in a hepatoma cell line that produced erythropoietin, but subsequently was shown to be present in many more cell types. It is a heterodimer consisting of HIF$1 \alpha$ and HIF- $1 \beta$ subunits. It is now recognized that several hundred genes are either directly or indirectly regulated by HIF. The discovery of HIF has been a great step forward in our comprehension of hypoxia response. HIF-1 is a transcription factor that is a key regulator of oxygen homeostasis, and, in addition to erythropoietin, HIF-1 responsive genes include regulators of functions such as cellular energy metabolism, iron metabolism, catecholamine metabolism, vasomotor control, and angiogenesis, suggesting an important role in the coordination of oxygen supply and cellular metabolism (reviewed in Semenza, 2004).

The primary mode of HIF regulation is through proteasomal degradation, which requires the presence of the von Hippel-Lindau (VHL) tumor suppressor protein to act as the recognition component of a ubiquitin E3 ligase complex. The interaction between HIF and VHL is brought about by the hydroxylation of two proline residues (in both HIF- $1 \alpha$ and HIF- $2 \alpha$ ). The transactivation domain function of HIF- $1 \alpha$ has also been shown to be regulated by asparaginyl hydroxylation in an $\mathrm{O}_{2}$-dependent manner (Semenza, 2004). These catalytic reactions will be significantly affected by variation in substrate, in enzyme concentration, and any structural variations that affect the reaction rates. Genetic variation surrounding these key $\mathrm{O}_{2}$-sensing steps therefore has the potential to influence greatly the overall function of the HIF system. In mice partially deficient for HIF-1, exposure to chronic hypoxia induces less pulmonary hypertension, and they have pulmonary vascular myocytes that depolarize less with hypoxia and have impaired carotid body and ventilatory acclimatization responses to hypoxia compared with control animals (Yu et al., 1999; Shimoda et al., 2001; Kline et al., 2002).

Modifications within the HIF pathway may give rise to the very marked variations in the responses of normal humans to hypoxia. Thus, interindividual variation in HIF-regulated gene expression at the cellular level may relate to variations in responses at the integrative level. Appenzeller et al. (2006) have found correlations between the high levels of expression of several genes, including HIF-1, symptoms at high altitude, and CMS. They also underscore the changes in gene expression levels in CMS subjects after arrival to sea level, where their values never reached sea-level values. This may indicate the existence of alterations in regulators of HIF- $1 \alpha$, keeping higher levels in the absence of hypoxia stimulus. With another approximation, using genetic markers located 
in close proximity to the HIF- $1 \alpha$ gene and to genes that regulate its stabilization and degradation, such as von Hippel-Lindau (VHL), "prolyl hydroxylase domain containing" 1, 2, 3 (PHD1, PHD2, PHD3), and phosphatase and tensin homologue deleted on chromosome 10 (PTEN), Mejía et al. (2005) addressed the association with severe polycythemia and CMS in CMS subjects and high-altitude controls, and found no evidence of association. But this does not exclude variations in these genes contributing to polycythemia and possibly CMS. Indeed, mutations in the PHD2 gene have been reported to be associated with familial erythrocytosis (Percy et al., 2006) and erythrocytosis with unidentified etiology (Al-Sheikh et al., 2008). Thus, taking into account the still reduced data that links HIF1 with polycythemia and CMS, its role in this disease remains to be defined.

\section{Erythropoiesis genes}

Erythropoietin (EPO) is a hormone that has a very important erythroid function, but also nonerythroid purposes; it protects the brain from ischemia and the spinal cord and retina from injury in humans and mice, among others functions (Höpfl et al., 2003). HIF-1 $\alpha$ is the key regulator of EPO production. Oxygen deficiency stimulates both HIF and EPO production, which, in turn, increases red cell production, the outstanding sign of CMS. In CMS, EPO is variably expressed, but in patients with very high hemoglobin concentrations, EPO is usually highly expressed (León-Velarde et al., 1991).

As part of the genetic association analysis performed by Mejía et al. (2005), erythropoietin (EPO) and erythropoietinreceptor (EPOR) genes were also included as functional candidate genes. Further, Mejía et al. (unpublised data) sequenced the coding and downstream regulatory regions of the EPO gene from cell lines derived from the high altitude natives studied and found no variations in the coding sequences, intron-exon boundaries, or any regulatory domain. The association between the polymorphisms linked to EPO and EPOR and erythremia failed to show evidence of a major monogenic contribution of the loci tested to excessive erythocytosis in CMS. This seems to indicate that the excessive erythropoiesis might be caused by factors other than the changes in the EPO gene. However, we cannot exclude the possibility that variations in the studied genes contribute to the risk of erythremia and CMS. The role of the high EPO levels in the genesis of CMS, if there is one, is still waiting to be elucidated.

\section{Endothelial nitric oxide synthase (eNOS)}

The synthesis of nitric oxide (NO) is catalyzed by endothelial nitrate synthase (eNOS), among other oxide synthases. eNOS catalyzes the oxidation of the amino acid LArginine to give rise to citruline and NO. NO activates a soluble guanylate cyclase and elicits smooth muscle relaxation by protein kinase activation. Thus, eNOS is a key catalytic enzyme responsible for providing NO release in the vascular bed, in general, and of basal pulmonary NO release, in particular, thus playing an important role in vessel tone, blood pressure, and blood flow (Garg and Hassid, 1989; Sarker et al., 1996).

Hypoxia regulates the activity and endothelial cell expression of genes, including eNOS (Coulet et al., 2003), and the association of polymorphisms in this gene with hypoxia is ex- pected to alter vascular mechanical forces and vascular remodeling. Based on these data, it has been put forward that eNOS gene mutations might be involved in the pathogenesis of HAPH. Thus, in several high altitude populations, the G894T [nucleotide substitution in exon 7, which causes amino acid substitution of glutamic acid (Glu) by aspartic acid (Asp) at the 298th position] and 4B/4A (27-bp variable number of tandem repeats (VNTR) within intron 4] polymorphisms have been examined. Overall, the T allele has been found to be associated with vascular disorders and pulmonary hypertension that are mediated by NO (Hampl and Herget, 2002), without modifying the NO-mediated vascular responses (Sofowora et al., 2001). This polymorphism might indeed have physiological significance in the presence of endothelial dysfunction. The 27-bp VNTR is perhaps less likely to be functional; in fact, conflicting associations between the intron 4 polymorphism and nitric oxide pathway activity have been described. Among the populations who live exposed to chronic hypoxia, blood flow is likely to be a major determinant of oxygen delivery; accordingly, recent research among Andean highlanders demonstrates that an increased NO synthesis is an essential attribute for oxygen delivery at high altitude by allowing better pulmonary perfusion (Beall et al., 2001).

In Asia, the Sherpa adaptation to high altitude has been hypothesized as being due to a genetic basis, because they have had a considerable period of time for gene selection against different life-threatening high altitude diseases, for example, against HAPH. In this sense, Ahsan et al. (2005) investigated the role of the eNOS gene in high altitude adaptation among Ladakh natives (over $3600 \mathrm{~min}$ India). They reported that wild-type alleles $G$ and $4 b$ were significantly overrepresented in these natives, and the combination of wild-type genotypes GG and BB, which contributed to the higher NO levels, were associated with high altitude adaptation. More recently, Droma et al. (2006) have postulated that the wild-type alleles of these polymorphisms may be a benefit for Sherpa adaptation to high altitude, based on the finding that the frequencies of these alleles were also significantly higher in Sherpas at $3440 \mathrm{~m}(n=105$; G: 85.7\%; B: 96.7\%) than in non-Sherpa Nepalis (G: 77.9\%; B: 90.5\%). In addition, the combination of GG and BB was significantly greater in Sherpas $(66.7 \%)$ than in non-Sherpas $(47.7 \%)$ (Table 1). They also measured serum concentrations of the metabolites of NO (nitrite and nitrate) and found that they were significantly lower in Sherpas $(53.2 \pm 4.6 \mu \mathrm{mol} / \mathrm{L})$ than

Table 1. Genotype and Allele Frequencies of the enOS Polymorphism in Lowlands (LL, SEA Level), Highlands (HL, Andeans), and Chronic Mountain Sickness (CMS) Subjects, Cerro de Pasco, Perú (4300 m)

\begin{tabular}{lccc}
\hline Genotypes & $\begin{array}{c}L L(\mathrm{n}=57) \\
\mathrm{n}(\%)\end{array}$ & $\begin{array}{c}H L(\mathrm{n}=48) \\
\mathrm{n}(\%)\end{array}$ & $\begin{array}{c}C M S(\mathrm{n}=42) \\
\mathrm{n}(\%)\end{array}$ \\
\hline GG & $41(72)$ & $38(79)$ & $32(76)$ \\
GT & $15(26)$ & $10(21)$ & $9(22)$ \\
TT & $1(2)$ & $0(0)$ & $1(2)$ \\
G & $97(85)$ & $86(90)$ & $73(87)$ \\
T & $17(15)$ & $10(10)$ & $11(13)$ \\
\hline
\end{tabular}

From Mejía et al., 2000. 
in non-Sherpas $(107.3 \pm 9.0 \mu \mathrm{mol} / \mathrm{L})$. However, the concentration values had very wide ranges and were not associated with the eNOS polymorphisms.

Exaggerated constriction of vessels in the lungs appears to contribute to both HAPH and high altitude pulmonary edema (HAPE) (Maggiorini and León Velarde, 2003). In line with this proposition, well-adapted high altitude populations exhaled significantly higher concentrations of NO compared to lowland populations (Beall et al., 2001), but HAPE patients had lessened NO in their lungs (Busch et al., 2001). Despite the similarities of the acute (HAPE) and chronic (HAPH) diseases, Droma et al. (2002), in Japan, found that rare alleles of G894T and 4B/4A polymorphisms in the eNOS gene occurred significantly more often in subjects who suffered HAPE than in a group of mountain climbers who had never experienced the condition. In contrast with the notion that these polymorphisms may be a benefit for the Sherpa adaptation to high altitude, the HAPE group was healthy and athletic at low altitudes, but suffered HAPE at least once while mountain climbing. The control group, on average, had made more than 100 climbs at elevations exceeding 2800 $\mathrm{m}$ above sea level without experiencing HAPE. Only $9.8 \%$ of the control group carried the G894T polymorphism, compared with $25.6 \%$ of the HAPE patients. Regarding the $4 \mathrm{~B} / 4 \mathrm{~A}$ polymorphism, Druma et al. found that the variations occurred in $6.9 \%$ of the control group and in $23.2 \%$ of the HAPE patients; and $26.8 \%$ of the HAPE group, but none of the control group, carried the two eNOS polymorphisms. The difference between both studies by Droma et al. (2002 and 2006) might be explained based on the proportion of each polymorphism found in each population. Actually, the use of pulmonary pressure as a continuous outcome together with a gene-based approach using SNPs could be used as a more informative approach for assessing the effect of the NOS3 variation on HAPH or HAPE.

In high altitude Amerindian natives living at 4300 m, Mejía et al. (2000) were not able to show that normal high altitudes natives or CMS subjects have a different prevalence of the G894T and 4B/4A polymorphisms, as happens in Sherpas (Tables 1 and 2) (Droma et al., 2006). However, it should be mentioned, that the pathological profile of chronic high altitude diseases is very different between Asian and Andean populations (Groves et al., 1993; Leon-Velarde et al., 2005). In addition, in the evolutionary time scale at high altitude,

Table 2. Genotype and Allele Frequencies of the eNOS Polymorphism in Non-Sherpas (LL, Sherpa NePALIS RESIDING IN KATHMANDU, $1330 \mathrm{M})$ AND IN HighlandS SubJects (HL, SHERPAS, NAMCHE BAZAAR, 3440 M)

\begin{tabular}{lcc}
\hline Genotypes & $\begin{array}{c}L L(\mathrm{n}=111) \\
\mathrm{n}(\%)\end{array}$ & $\begin{array}{c}H L(\mathrm{n}=105) \\
\mathrm{n}(\%)\end{array}$ \\
\hline GG & $68(61)$ & $76(72)$ \\
GT & $37(33)$ & $28(27)$ \\
TT & $6(5)$ & $1(1)$ \\
G & $173(78)$ & $180(86)^{*}$ \\
T & $49(22)$ & $30(14)$ \\
\hline
\end{tabular}

${ }^{*} p<0.05$ when compared with LL.

From Droma et al., 2006. the altitude of residence between Sherpas and Andeans is rather different.

\section{Angiotensin-converting enzyme (ACE)}

ACE is a component of the renin-angiotensin system (RAS), which is involved in the regulation of blood pressure and blood flow and volume. ACE activates the potent vasoconstrictor angiotensin II, which regulates pressure, as well as water and salt retention, by stimulation of aldosterone release. But ACE also degrades bradykinin by activation of the $\mathrm{BK}_{2}$ receptor, which stimulates the release of nitric oxide and prostaglandins and may counteract Ang II-mediated effects (Zisman, 1998). Because of these important effects, some studies, such as that of Morrell et al. (1995) in rats, have implicated ACE in the etiology of hypoxia-induced pulmonary hypertension. However, it should be taken into account that different effects of ACE inhibitors on the affinity of the enzyme have raised the question that tissue-bound ACE might have a different effect than that of circulating ACE. In fact, it has been reported that ACE inhibitors with more hydrophobic moieties have a greater affinity for the C-terminal than for the N-terminal active site of the enzyme. This differential affinity could be further modulated by organ type. Although the mechanism for these organ-specific effects is not known, it has been proposed that the two active sites of ACE may interact differently with particular ACE inhibitors, and the specific organ in which ACE is tissue bound may also affect the inhibitor affinity for the active sites of the enzyme (Zisman, 1998).

The gene for human ACE is located on chromosome 17, and a frequently studied polymorphism is the $287 \mathrm{bp}$ Alu insertion (I)/deletion (ID) polymorphism located in intron 16 (Rigat et al., 1990). The I allele has been associated with lower ACE protein function compared to the D (Danser et al., 1995; Costerousse et al., 1997). Serum ACE levels and the RAS system are modified by hypoxia (Milledge and Catley, 1984), and these effects in turn may mediate the cardiopulmonary responses to high altitude.

Montgomery et al. (1998) reported an overrepresentation of the I allele in elite mountaineers who ascended beyond $8000 \mathrm{~m}$ without supplemental oxygen, suggesting an I-allele performance benefit for mountaineers ascending to extreme altitude. In another study of recreational climbers $(n=248)$ who climb to $4800 \mathrm{~m}$, the I allele again predicted success in reaching the summit (Tsianos et al., 2005), and Alvarez et al. (2000) have also shown that the I allele occurred at a significantly higher frequency in elite athletes $(n=120)$ compared to controls. To explain this apparent performance benefit, there is evidence that individuals of I/I genotype maintain higher arterial oxygen saturation $\left(\mathrm{Sa}_{\mathrm{O}_{2}}\right)$ at rest and during exercise at high altitude. A study shows that subjects of European ancestry with the I/I genotype who ascended to above $5000 \mathrm{~m}$ in 12 days were able to maintain higher $\mathrm{Sa}_{\mathrm{O}_{2}}$, especially as altitude increased (Woods et al., 2002). In addition, Patel et al. (2003) have shown that the hypoxia-induced rise in minute ventilation was significantly greater among those of II genotype (4.1\% vs. $2.2 \%$ for II versus DD) in subjects ( $n=60 ; 14 \mathrm{II}, 30 \mathrm{ID}, 16 \mathrm{DD})$ who exercised for 6 $\min$ at $50 \%$ of the workload at the ventilatory threshold, while breathing $12.5 \%$ oxygen. Bigham et al. (2008) have also shown an association of ACE I/I genotype with higher resting and submaximal exercise $\mathrm{Sa}_{\mathrm{O}_{2}}$ in two groups of Peru- 
vians (one born at sea level, with high altitude ancestors, and one born at high altitude) who were tested at $4300 \mathrm{~m}$. In both study groups, individuals of I/I genotype maintained an $\sim 2.3$ percentage point higher $\mathrm{Sa}_{\mathrm{O}_{2}}$, explaining about $4 \%$ of the total variance in resting and exercise values. These authors suggest that central cardiopulmonary effects of ACE could underlie the association of the I allele with ventilation and $\mathrm{Sa}_{\mathrm{O}_{2}}$. Indeed, angiotensin II modulates hypoxia-induced pulmonary vasoconstriction (Kiely et al., 1995), and differences in circulating ACE could affect ventilation-perfusion $(\mathrm{V} / \mathrm{Q})$ relationships within the lung.

There is also evidence that native groups such as the Quechua have an increased I-allele frequency (0.72). However, the Quechua I-allele frequency does not appear to be increased relative to all other Native American populations. In fact, many low altitude Native Americans exhibit I-allele frequencies greater than that observed in Quechua (Rupert et al., 1999). Also, in the highland native Ladakhis from Northern India, the I-allele frequency has been documented at 0.67 (Qadar Pasha et al., 2001). These frequencies are slightly higher than the mean European, African, or Asian I-allele frequencies in the literature. In the Kyrgyz population, Aldashev et al. (2002) found that I-allele frequencies differed between highlanders and lowlanders (I allele being more frequent in lowlanders, but, on average were similar to that found in other Asian populations. This difference might be explained by the fact that their lowland control group was recruited from patients attending hospitals and thus may not have been representative of the Bishkek male population. Aldashev et al. have also shown that the variance in plasma ACE activity that could be attributed to the ACE I/D polymorphism was $16.3 \%$, compared with $28 \%$ in a European population (Tiret et al., 1992). The explanation given for this difference is that plasma ACE activity in the Kyrgyz population could be under greater control from other polymorphisms in the ACE gene or other regulatory genes.

With regard to $\mathrm{HAPH}$, the Kyrgyz revealed threefold higher frequency of I/I genotype at high altitude in subjects

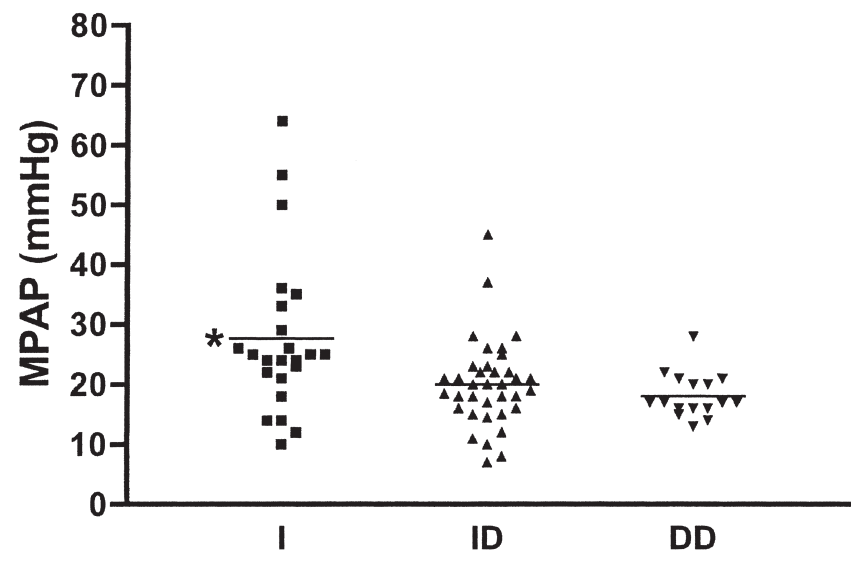

ACE Genotype

FIG. 1. Distribution of pulmonary arterial pressures of male highlanders according to ACE genotype. The mean pulmonary arterial pressure (MPAP) was higher in the I/I genotype group than in the I/D or D/D genotype group. ${ }^{*} p<$ 0.05. From Aldashev et al., 2002.

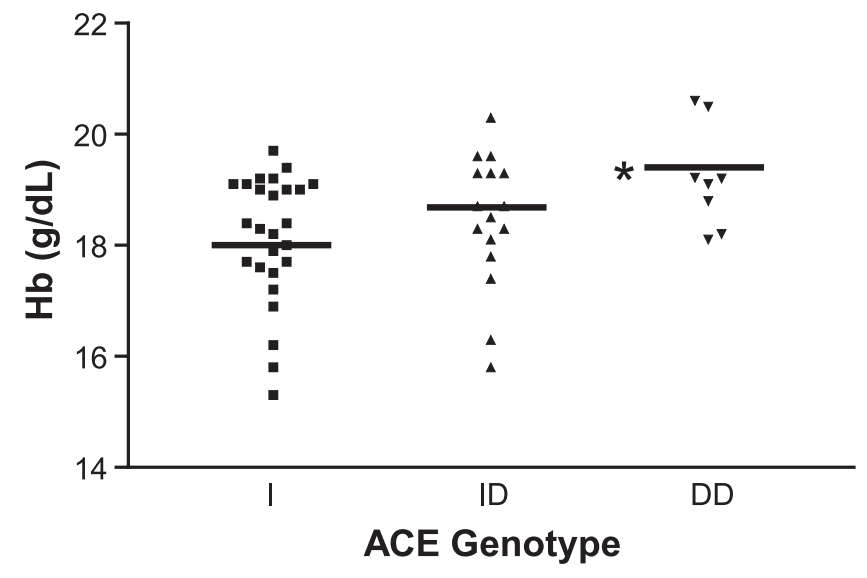

FIG. 2. Distribution of hemoglobin concentrations of healthy male highlanders according to ACE genotype. The mean hemoglobin concentrations $(\mathrm{Hb})$ was higher in the $\mathrm{D} / \mathrm{D}$ genotype group than in the I/I genotype group. ${ }^{*} p<$ 0.05 .

with this condition (Morrell et al., 1999; Aldashev et al., 2002) (Fig. 1). As mentioned, the highland Kyrgyz had lower I-allele frequency $(0.56, n=87)$ compared to a Bishkek lowland control group. However, the Aldashev et al. study has determined that $\mathrm{HAPH}$, as defined by the prevalence of ECG signs of right ventricular hypertrophy in the absence of chronic airflow obstruction, is much more common among the highland population of Kyrgyzstan than in other high altitude populations, likely because the Kyrgyz migrated to the Tien-Shan and Pamir Mountains from lower altitudes relatively recently, in about the 9th and 10th centuries AD, thus with a shorter period of time for selection against $\mathrm{HAPH}$.

In contrast to the Kyrgyz, the Amerindian population at high altitude show more prevalence of EE than of HAPH. When evaluated for the ACE polymorphism, hemoglobin was higher in healthy highlanders with the D/D genotype $(19.2 \pm 1.1 \mathrm{~g} / \mathrm{dL})$ compared with the natives with I/I genotype $(18.0 \pm 1.3 \mathrm{~g} / \mathrm{dL} ; p<0.05)$ (Mejía et al., 2000) (Fig. 2). If I/I genotype is associated with a good athletic performance and with good capacity to maintain a high $\mathrm{Sa}_{\mathrm{O}_{2}}$ as altitude increased, it can be speculated that the higher hemoglobin concentrations with the D/D genotype is due, in part, to their poor capacity to maintain a higher $\mathrm{Sa}_{\mathrm{O}_{2}}$ at their altitude of residence.

In relation to the differences between Andean and Kyrgyz populations (Tables 3 and 4), it could also be speculated that the ACE I/I genotype represents a genetic marker for HAPH susceptibility, independent of its effects on ACE activity in other systems. Aldashev et al. (2002) also hypothesized that subjects with the I/I genotype may have enhanced endurance performance, as described in elite athletes. An increased level of exercise would lead to an elevation of cardiac output and pulmonary artery pressure, exacerbating any tendency to $\mathrm{HAPH}$. With regard to the higher hemoglobin in highlanders with the D/D genotype, as the I allele has been associated with lower ACE protein function compared to the D allele, a preponderate D/D genotype might indicate higher ACE protein function and higher levels of angiotensin II. This, in turn, would constrict the vascular smooth muscle cells and play a role in vessel tone, blood flow, and thus blood pressure, which 
Table 3. Genotype and Allele Frequencies of the ACE I/D Polymorphism in LoWlands (LL, SEa Level), Highlands (HL) Andeans and Subjects with Chronic Mountain Sickness (CMS), Cerro de PAsco, Perú $4300 \mathrm{~m}$

\begin{tabular}{lccc}
\hline Genotypes & $\begin{array}{c}L L(\mathrm{n}=57) \\
\mathrm{n}(\%)\end{array}$ & $\begin{array}{c}H L(\mathrm{n}=48) \\
\mathrm{n}(\%)\end{array}$ & $\begin{array}{c}C M S(\mathrm{n}=42) \\
\mathrm{n}(\%)\end{array}$ \\
\hline II & $20(35)$ & $27(57)^{*}$ & $23(54)^{*}$ \\
ID & $26(46)$ & $18(38)$ & $14(33)$ \\
DD & $11(19)$ & $3(5)$ & $5(13)$ \\
I & $66(58)$ & $73(76)^{*}$ & $60(71)^{*}$ \\
D & $48(42)$ & $23(24)^{*}$ & $24(29)^{*}$ \\
\hline
\end{tabular}

From Mejía et al., 2000.

${ }^{*} p<0.05$ when compared HL and CMS with LL.

is increased in CMS, in contrast with normal high altitude populations, who have a tendency to present lower systemic blood pressure levels (Banchero et al., 1966; Marticorena et al., 1969). Unfortunately, the level of ACE in plasma has not been measured along with the frequency of ACE D/D genotype; thus this genetic marker could also be independent of its effects on ACE activity.

As Rupert et al. (1999) pointed out, from the accessible data it is difficult to verify natural selection as an explanation for the relatively low D-allele frequency in high altitude Quechua. As well, natural selection cannot be adopted as an explanation for the relatively high I-allele frequency in high altitude Kyrgyz. Unfortunately, the ACE I/D polymorphism is still poorly understood, and it is likely that the adaptive process involves the selection of alleles at multiple loci with beneficial effects on the phenotype, which can also include a gene-gene interaction related to the different ethnic altitude of origin.

\section{Vascular endothelial growth factor (VEGF)}

VEGF is an important signaling protein involved in both vasculogenesis and angiogenesis. VEGF activity has been mostly studied in cells of the vascular endothelium, although it does have effects on a number of other cell types (e.g., stimulation monocyte/macrophage migration, neurons, cancer cells, kidney epithelial cells). In vitro, VEGF has been shown to stimulate endothelial cell mitogenesis and cell migration. VEGF is also a vasodilator, and increases microvascular permeability; it was originally referred to as vascular permeability factor (Gibbons and Dzau, 1994; Dvorak et al., 1995).

The degree of induction by hypoxia of VEGF in peripheral blood monocytes correlates both with the degree of formation of collateral blood vessels in coronary heart disease (Schultz et al., 1999). In relation to HIF, which regulates VEGF production, a single nucleotide (C to T) polymorphism (SNP) in exon 12 of HIF-1 $\alpha$ that changes residue 582 of HIF$1 \alpha$ from proline to serine has been shown to be associated with significantly less collateral vessel formation in patients with ischemic heart disease (Resar et al., 2005). Even though the VEGF dimeric protein could be composed of 121, 165, 189 , or 206 amino acid subunits, the main VEGF isoform expressed by many cell types is VEGF165. Appenzeller et al. (2006) found that, when measuring VEGF121 and VEGF165 subunits, the latter have significantly higher expression in CMS patients in CP $(p=0.006)$ compared with controls. VEGF 165 was negatively correlated with arterial saturation
$(R=0.79 ; p<0.001)$ in CMS patients. These findings could be related to its angiogenic effects, or to VEGF's role in neuroprotection. VEGF is a modifier of motor neuron degeneration and is involved in neuronal death in spinal cord and cerebral ischemia. There is evidence of its role in ischemic neuropathy, nerve regeneration, Alzheimer's disease, and multiple sclerosis (Storkbaum et al., 2004). Thus, increased VEGF expression, as found in CMS, might also be related to neuron survival and/or neurodegeneration protection in chronic hypoxia (Appenzeller et al., 2006).

\section{Other Candidate Genes That Have Been Related to Hypoxia Tolerance}

Phosphoglycerate kinase (PGK)

Another hallmark of cellular responses to hypoxia is the upregulation of oxygen-independent metabolic pathways to supply the additional energy necessary for cell survival under diminished oxygen availability. Thus, in hypoxia, enzymes involved in the glycolytic pathway and glucose transporters are upregulated by HIF-1, including PGK 1 (Seagroves et al., 2001).

PGK is involved in the transformation of 1,3-disphosphoglycerate into 3 phosphoglycerate and ATP production, an important step in glycolysis. The gene coding for PGK, which is expressed in every tissue except testes, is located on the $X$ chromosome. Gene structure, cDNA, and protein sequences have been identified, and a few mutations have been described. Patients present with hemolytic anemia, which may be associated with various neurological disorders. Some individuals are affected by muscular disorders alone or these combined with hemolytic anemia (Beutler, 2007).

In CMS, the PGK 1gene has been found to be expressed at higher levels than in the white cells of HA normal natives at $4300 \mathrm{~m}$ (Appenzeller et al., 2006). These proteins are also upregulated by oxidative stressors at sea level and may be associated with the release of reactive oxygen species (ROS), which are implicated in aging. However, it could be also hypothesized that an upregulation of oxygen-independent metabolic pathways, like the glycolytic pathway and glucose transporters, might be necessary to supply the additional energy necessary for cell survival under severe hypoxemia, for example, in subjects with CMS (Appenzeller et al., 2006).

Table 4. Genotype and Allele Frequencies of the ACE I/D Polymorphism in LOWLANDS (LL) AND HighlandS (HL) Kyrgyz and in Highlands Subjects With High Altitude Pulmonary Hypertension (HAPH), Naryn Area, 2800 to 3100 m AbOVe Sea LeVel, or Pamir Region, 3200 to 3600 m above Sea Level

\begin{tabular}{lccc}
\hline $\begin{array}{l}\text { Genotypes } \\
\text { and alleles }\end{array}$ & $\begin{array}{c}L L(\mathrm{n}=212) \\
\mathrm{n}(\%)\end{array}$ & $\begin{array}{c}H L(\mathrm{n}=30) \\
\mathrm{n}(\%)\end{array}$ & $\begin{array}{c}H A P H(\mathrm{n}=48) \\
\mathrm{n}(\%)\end{array}$ \\
\hline $\mathrm{II}$ & $90(43)$ & $4(13)$ & $21(44)^{*}$ \\
$\mathrm{ID}$ & $96(45)$ & $15(50)$ & $22(46)$ \\
$\mathrm{DD}$ & $26(12)$ & $11(37)$ & $5(10)$ \\
$\mathrm{I}$ & $276(65)$ & $23(38)$ & $64(67)^{+}$ \\
$\mathrm{D}$ & $148(35)$ & $37(62)$ & $32(33)$ \\
\hline
\end{tabular}

From Aldashev et al., 2002.

${ }^{*} p<0.003 ;{ }^{\dagger} p<0.0005$ when compared HL subjects. 
Heme oxygenase-1 (HMOX-1), heat shock protein 70 (hsp70), ataxia telangiectasia mutated (ATM)

Stressed mammalian cells upregulate heme oxygenase, which catabolizes heme to biliverdin, carbon monoxide, and free iron. Heme oxygenase occurs as two isozymes, an inducible heme oxygenase-1 (HMOX-1) on chromosome 22 and a constitutive heme oxygenase- 2 on chromosome 16 (Bainbridge and Smith, 2005). Expression of heat shock protein 70 (hsp70) is stimulated during ischemia and stress and also participates in innate immunity (Li et al., 2002; Schmitt et al., 2006) . Ataxia telangiectasia mutated (ATM), a phosphatidylinositol-3-OH-kinase-like serine/threonine kinase, and the related ATR (ATM and Rad3 related) kinase regulate cellular responses to DNA damage by controlling cell cycle arrest and DNA repair pathways when recruited and activated by DNA double-strand breaks. It is a well-characterized tumor suppressor that plays a key role in the maintenance of genomic stability, with functions in cell cycle arrest and apoptosis (Smith et al., 1999). Knockout mice lacking the ATM protein exhibit impaired detection and repair of DNA damage and increased embryopathies (Bhuller et al., 2006).

When RNA is extracted from venous blood white cells of CMS patients and evaluated for the gene expression of HMOX-1, hsp70 and ATM, significantly higher levels have been found in CMS when compared with Andean controls at $4300 \mathrm{~m}$ (Appenzeller et al., 2006). Hence, these results may be associated with increased apoptosis or, alternatively, with the development of, as yet to be determined, mechanisms for cellular protection that mitigate the effects of increased cellular death rates and aging.

However, in the Appenzeller (2006) study it would have been worthwhile to consider the inclusion of alternative covariates in the analysis (e.g., age) and evaluate if, after adjusting for multiple comparisons, $p$-values could be still considered significant. Unfortunately, the number of subjects was too small to allow these kinds of comparisons.

\section{Conclusion}

With no doubt, genetic studies will have important implications for the etiology of CMS and HAPH. However, concerning the exploration of the polymorphisms that are related to the different hypoxic responses, published data to date are insufficient for a rigorous test of any hypothesis, probably because the genetic effects are small (polygenic). In addition, gene-gene or gene-environment interaction should be taken into account in the search for a genetic cause of these high altitude diseases. In future studies we also recommended the use of SNP databases and genome-wide haplotype mapping to increase the power to detect the association between a potential susceptibility loci and CMS or HAPH or, alternatively, with the main characteristics of these diseases, that is, hypoventilation and/or EE and pulmonary hypertension.

Also, it is worthwhile to note that the variability of the results obtained in the genes studied so far seems to indicate that the genetic background of the populations is so vast that the findings could represent instead genetic markers for other susceptibilities, independent of the effects on the downward effectors in the suspected systems affected by CMS and/or HAPH. Different and combined approaches may help to identify the genetic basis responsible for the intolerance to hypoxia in different high altitude populations and should finally help to identify individuals at increased risk of CMS and HAPH.

\section{References}

Ahsan A., Norboo T., Baig M.A., and Qadar Pasha M.A. (2005). Simultaneous selection of the wild-type genotypes of the G894T and 4B/4A polymorphisms of NOS3 associated with high-altitude adaptation. Ann. Hum. Genetics 69(Pt 3):260267.

Al-Sheikh M., Moradkhani K., Lopez M., Wajcman H., and Prehu C. (2008). Disturbance in the HIF- $1 \alpha$ pathway associated with erythrocytosis: further evidences brought by frameshift and nonsense mutations in the prolyl hydroxylase domain protein 2 (PHD2) gene. Blood Cells Mol. Dis. 40(2): 160-165.

Aldashev A., Sarybaev A.S., Sydykov A.S., Kalmyrzaev B.B., Kim E.V., Mamanova L.B., Maripov R., Kojonazarov B.K., Mirrakhimov M.M., Wilkins M.R., and Morrell N.W. (2002). Characterization of high-altitude pulmonary hypertension in the Kyrgyz, Am. J. Resp. Crit. Care Med. 166:1396-1402.

Alvarez R., Terrados N., Ortolano R., Iglesias-Cubero G., Reguero J.R., Batalla A., Cortina A., Fernández-García B., Rodríguez C., Braga S., Alvarez V., and Coto E. (2000). Genetic variation in the renin-angiotensin system and athletic performance. Eur. J. Appl. Physiol. 82(1-2):117-120.

Anand I.S., and Wu T. (2004). Syndromes of subacute mountain sickness, High Alt. Med. Biol. 5:156-170.

Antezana A.M., Antezana G., Aparicio O., Noriega I., León-Velarde F., and Richalet J.-P. (1998). Pulmonary hypertension in high-altitude chronic hypoxia: response to nifedipine. Eur. Respir. J. 12:1181-1185.

Appenzeller O., Minko T., Qualls C., Pozharov V., Gamboa J., Gamboa A., and Wang Y. (2006). Gene expression, autonomic function and chronic hypoxia: lessons from the Andes. Clin. Auton. Res. 16:217-222.

Arias-Stella J., and Saldaña M. (1963). The terminal portion of the pulmonary arterial tree in people native to high altitudes. Circulation. 28:915-925.

Bainbridge S.A., and Smith G.N. (2005). Heme oxygenase in human diseases. Free Radical Biol. Med. 38:979-988.

Banchero N., Sime F., Peñaloza D., Cruz J.C., Gamboa R., and Marticorena E. (1966). Pulmonary pressure, cardiac output, and arterial oxygen saturation during exercise at high altitude and at sea level. Circulation. 33:249-262.

Beall C.M., Brittenham G.M., Strohl K.P., Blangero J., WilliamsBlangero S., Goldstein M.C., Decker M.J., Vargas E., Villena M., Soria R., Alarcon A.M., and Gonzales C. (1998). Hemoglobin concentration of high-altitude Tibetans and Bolivian Aymara. Am. J. Phys. Anthropol. 106:385-400.

Beall C.M., Laskowski D., Strohl K.P., Soria R., Villena M., Vargas E., Alarcón A.M., Gonzales C., and Erzurum S.C. (2001). Pulmonary nitric oxide in mountain dwellers. Nature. 414: 411-412.

Bernardi L., Roach R.C., Keyl C., Spicuzza L., Passino C., Bonfichi M., Gamboa A., Gamboa J., Malcovati L., Schneider A., Casiraghi N., Mori A., and León-Velarde F. (2003). Ventilation, autonomic function, sleep and erythropoietin. Chronic mountain sickness of Andean natives. Adv. Exp. Med. Biol. 543:161-175.

Beutler E. (2007). PGK deficiency. Brit. J. Haematol. 136:3-11.

Bhuller Y., Jeng W., and Wells P.G. (2006). Variable in vivo embryoprotective role for ataxia-telangiectasia-mutated against 
constitutive and phenytoin-enhanced oxidative stress in atm knockout mice. Toxicol. Sci. 93:146-155.

Bigham A., Kiyamu M., León-Velarde F., Parra E.J., Rivera-Ch M., Shriver M.D., and Brutsaert T.D. (2008). Angiotensin-converting enzyme genotype and arterial oxygen saturation at high altitude in Peruvian Quechua. High Alt. Med. Biol. 9:167-178.

Busch T., Bärtsch P., Pappert D., Grünig E., Hildebrandt W., Elser H., Falke K.J., and Swenson E.R. (2001). Hypoxia decreases exhaled nitric oxide in mountaineers susceptible to high-altitude pulmonary edema. Am. J. Respir. Crit. Care Med. 163:368-373.

Costerousse O., Danilov S., and Alhenc-Gelas F. (1997). Genetics of angiotensin I-converting enzyme. Clin. Exp. Hypertens. 19(5-6):659-669.

Coulet F., Nadaud S., Agrapart M., and Soubrier F. (2003). Identification of hypoxia-response element in the human endothelial nitric-oxide synthase gene promoter. J. Biol. Chem. 278:46230-46240.

Cruz J.C., Díaz C., Marticorena E., and Hilario V. (1969). Phlebotomy improves pulmonary gas exchange in chronic mountain polycythemia. Respiration. 38:305-313.

Danser A.H., Schalekamp M.A., Bax W.A., van den Brink A.M., Saxena P.R., Riegger G.A., and Schunkert H. (1995). Angiotensin-converting enzyme in the human heart. Effect of the deletion/insertion polymorphism. Circulation. 92:1387-1388.

Droma Y., Hanaoka M., Ota M., Katsuyama Y., Koizumi T., Fujimoto K., Kobayashi T., and Kubo K. (2002). Positive association of the endothelial nitric oxide synthase gene polymorphisms with high-altitude pulmonary edema. Circulation. 106:826-830.

Droma Y., Hanaoka M., Basnyat B., Arjyal A., Neupane P., Pandit A., Sharma D., Miwa N., Ito M., Katsuyama Y., Ota M., and Kubo K. (2006). Genetic contribution of the endothelial nitric oxide synthase gene to high altitude adaptation in Sherpas. High Alt. Med. Biol. 7:209-220.

Dvorak, H.F., Brown, L.F., Detmar, M., and Dvorak, A.M. (1995). Vascular permeability factor/vascular endothelial growth factor, microvascular hyperpermeability, and angiogenesis. Am. J. Pathol. 146:1029-1039.

Ergueta J., Spielvogel H., and Cudkowicz L. (1971). Cardio-respiratory studies in chronic mountain sickness (Monge's syndrome). Respiration. 28:485-517.

Garg U.C., and Hassid A. (1989). Nitric oxide-generating vasodilators and 8-bromocyclic guanosine monophosphate inhibit mitogenesis and proliferation of cultured rat vascular smooth muscle cells. J. Clin. Invest. 83:1774-1777.

Ge R.-L. (1989). Small airway dysfunction in the patients with chronic mountain sickness [in Chinese]. Q. J. Med. 3:26-29.

Gibbons, G.H., and Dzau, V.J. (1994). The emerging concept of vascular remodeling. N. Engl. J. Med. 330:1431-1438.

Groves B.M., Droma T., Sutton J.R., McCullough R.G., McCullough R.E., Zhuang J., Rapmund G., Sun S., Janes C., and Moore L.G. (1993). Minimal hypoxic pulmonary hypertension in normal Tibetans at $3658 \mathrm{~m}$. J. Appl. Physiol. 74:312-318.

Hampl V., and Herget J. (2002). Role of nitric oxide in the pathogenesis of chronic pulmonary hypertension. Physiol. Rev. 80:1337-1372.

Höpfl G., Ogunshola O., and Gassmann M. (2003). Hypoxia and high altitude. The molecular response. In: Hypoxia: Through the Lifecycle, R.C. Roach, P.D. Wagner, and P.H. Hackett, eds. Kluwer Academic/Plenum Publishers, New York; pp. 98-116.

Hurtado A. (1942). Chronic mountain sickness. JAMA. 120: $1278-1282$.
Kiely D.G., Cargill R.I., and Lipworth B.J. (1995). Acute hypoxic pulmonary vasoconstriction in man is attenuated by type I angiotensin II receptor blockade. Cardiovasc. Res. 30:875-880.

Kline D.D., Peng Y.-J., Manalo D.J., Semenza G.L., and Prabhakar N.R. (2002). Defective carotid body function and impaired ventilatory responses to chronic hypoxia in mice partially deficient for hypoxia-inducible factor 1alpha. Proc. Natl. Acad. Sci. U.S.A. 99:821-826.

León-Velarde F., Monge C., Vidal A., Carcagno M., Criscuolo M., and Bozzini C.E. (1991). Serum immunoreactive erythropoietin in high altitude natives with and without excessive erythrocytosis. Exp. Hematol. 19:257-260.

León-Velarde F., Arregui A., Monge-C C., and Ruiz H. (1993). Ageing at high altitude and the risk of chronic mountain sickness. J. Wild. Med. 4:183-188.

León-Velarde F., Arregui A., Vargas M., Huicho L., and Acosta R. (1994). Chronic mountain sickness and chronic lower respiratory tract disorders. Chest. 106:151-155.

León-Velarde F., Rivera-Ch M., Tapia R., Huicho L., and MongeC C. (2001). Relationship of ovarian hormones to hypoxemia in women residents of $4300 \mathrm{~m}$. Am. J. Physiol. Regul. Integr. Comp. Physiol. 280:R488-R493.

León-Velarde F., Maggiorini M., Reeves J.T., Aldashev A., Asmus I., Bernardi L., Ge R.L., Hackett P., Kobayashi T., Moore L.G., Penaloza D., Richalet J.P., Roach R., Wu T., Vargas E., Zubieta-Castillo G., and Zubieta-Calleja G. (2005). Consensus statement on chronic and subacute high altitude diseases. High Alt. Med. Biol. 6:147-157.

Li Y., Subjeck J., Yang G., Repasky E., and Wang X.-Y. (2002). Kinetics of heat shock protein 70 synthesis in the human heart after cold cardioplegic arrest. Eur. J. Cardiothorac. Surg. 22: 415-420.

Lin C.P., and Wu T.Y. (1974). Clinical analysis of 286 cases of pediatric high altitude heart diseases. Chin. Med. J. 54 (suppl No. 6):99-100.

Maggiorini M., and León-Velarde F. (2003). High-altitude pulmonary hypertension: a pathophysiological entity to different diseases. Eur. Respir. J. 22:1019-1025.

Marticorena E., Ruiz L., Severino J., Gálvez J., and Peñaloza D. (1969). Systemic blood pressure in white men born at sea level: changes after long residence at high altitude. Am. J. Cardiol. 23:364-368.

Mejía O., León-Velarde F., and Espinoza J.R. (2000). ACE and eNOS gene polymorphism and Monge's disease. High Alt. Med. Biol. Abs. 59. 2:93.

Mejía O.M., Prchal J.T., León-Velarde F., Hurtado A., and Stockton D.W. (2005). Genetic association analysis of chronic mountain sickness in an Andean high-altitude population. Haematologica. 90:13-19.

Meyrick B., and Reid L. (1980). Hypoxia-induced structural changes in the media and adventitia of the rat hilar pulmonary artery and their regression. Am. J. Pathol. 100:151-178.

Milledge J.S., and Catley D.M. (1984). Angiotensin converting enzyme response to hypoxia in man: its role in altitude acclimatization. Clin. Sci. 67:453-456.

Monge-M C., and Monge-C C. (1966). High Altitude Diseases: Mechanism and Management. Charles C Thomas, Springfield, IL.

Monge-C C., Arregui A., and León-Velarde F. (1992). Pathophysiology and epidemiology of chronic mountain sickness. Int. J. Sports Med. 13:S79-S81.

Monge-C C., León-Velarde F., and Arregui A. (2001). Chronic mountain sickness in Andeans. In: High Altitude: An Exploration of Human Adaptation (Lung Biology in Health and Dis- 
ease, Vol. 161). T. F. Hornbein and R. B. Schoene, eds. Marcel Dekker, New York; pp. 815-838.

Montgomery H.E., Marshall R., Hemingway H., Myerson S., Clarkson P., Dollery C., Hayward M., Holliman D.E., Jubb M., World M., Thomas E.L., Brynes A.E., Saeed N., Barnard M., Bell J.D., Prasad K., Rayson M., Talmud P.J., and Humphries S.E. (1998). Human gene for physical performance. Nature. 393:221-222.

Morrell N.W., Atochina E.N., Morris K.G., Danilov S.G., and Stenmark K.R. (1995). Angiotensin converting enzyme expression is increased in small pulmonary arteries of rats with hypoxia-induced pulmonary hypertension. J. Clin. Invest. 96: 1823-1833.

Morrell N.W., Sarybaev A.S., Alikhan A., Mirrakhimov M.M., and Aldashev A.A. (1999). ACE genotype and risk of high altitude pulmonary hypertension in Kyrghyz highlanders. Lancet. 353:814.

Niermeyer S., Zamudio S., and Moore L.G. (2001). The people. In: High Altitude: An Exploration of Human Adaptation (Lung Biology in Health and Disease, Vol. 161). T. F. Hornbein and R. B. Schoene, eds. Marcel Dekker, New York; pp. 43-100.

Normand H., Vargas E., Bordachar J., Benoît O., and Raynaud J. (1992). Sleep apneas in high altitude residents (3800 m). Int. J. Sports Med. 13:S40-S42.

Patel S., Woods D.R., Macleod N.J., Brown A., Patel K.R., Montgomery H.E., and Peacock A.J. (2003). Angiotensin-converting enzyme genotype and the ventilatory response to exertional hypoxia. Respir. J. 22:755-760.

Peñaloza D., and Sime F. (1971). Chronic cor pulmonale due to loss of altitude acclimatization (chronic mountain sickness). Am. J. Med. 50:728-743.

Peñaloza D., Sime F., and Ruiz L. (1971). Cor pulmonale in chronic mountain sickness: present concept of Monge's disease. In: High Altitude Physiology: Cardiac and Respiratory Aspects. R. Porter and J. Knight, ed. Churchill Livingstone, Edinburgh; p. 41.

Percy M.J., Zhao Q., Flores A., Harrison C., Lappin T.R., Maxwell P.H., McMullin M.F., and Lee F.S. (2006). A family with erythrocytosis establishes a role for prolyl hydroxylase domain protein 2 in oxygen homeostasis. Proc. Natl. Acad. Sci. U.S.A. 103:654-659.

Qadar Pasha M.A., Khan A.P., Kumar R., Grover S.K., Ram R.B., Norboo T., Srivastava K.K., Selvamurthy W., and Brahmachari S.K. (2001). Angiotensin converting enzyme insertion allele in relation to high altitude adaptation. Ann. Hum. Genet. $65(\mathrm{Pt}$ 6):531-536.

Reeves J.T., and Weil J.V. (2001). Chronic mountain sickness. A view from the crow's nest. In: Hypoxia: From Genes to the Bedside. R. C. Roach, P. D. Wagner, and P. H. Hackett, eds. Kluwer Academic/Plenum Publishers, New York; pp 419437.

Resar J.R., Roguin A., Voner J., Nasir K., Hennebry T.A., Miller J.M., Ingersoll R., Kasch L.M. and Semenza G.L. (2005). Hypoxia-inducible factor 1 alpha\} polymorphism and coronary collaterals in patients with ischemic heart disease. Chest. 128:787-791.

Rigat B., Hubert C., Alhenc-Gelas F., Cambien F., Corvol P., and Soubrier F. (1990). An insertion/deletion polymorphism in the angiotensin I-converting enzyme gene accounting for half the variance of serum enzyme levels. J. Clin. Invest. 86:1343-1346.

Rupert J.L., Devine D.V., Monsalve M.V., and Hochachka P.W. (1999). Angiotensin-converting enzyme (ACE) alleles in the Quechua, a high altitude South American native population. Ann. Hum. Biol. 26:375-380.
Sarker R., Meinberg E.G., Stabley J.C., Gordon D., and Webb R.C. (1996). Nitric oxide reversibly inhibits the migration of cultured vascular smooth muscle cells. Circ. Res. 78:225-230.

Schultz A., Lavie L., Hochberg I., Beyar R., Stone T., Skorecki K., Lavie P., Roguin A., and Levy A.P. (1999). Interindividual heterogeneity in the hypoxic regulation of VEGF: significance for the development of the coronary artery collateral circulation. Circulation. 100:547-552.

Seagroves T.N., Ryan H.E., Lu H., Wouters B.G., Knapp M., Thibault P., Laderoute K., and Johnson R.S. (2001). Transcription factor HIF-1 is a necessary mediator of the Pasteur effect in mammalian cells. Mol. Cell. Biol. 21:3436-3444.

Semenza G.L. (2004). Hydroxylation of HIF-1: “Oxygen Sensing at the Molecular Level." Physiology. 19:176-182.

Severinghaus J.W., Bainton C.R., and Carcelén A. (1966). Respiratory insensitivity to hypoxia in chronically hypoxic men. Respir. Physiol. 1:308-334.

Schmitt J.P., Schunkert H., Birnbaum D.E., and Aebert H. (2006). Generation of anti-tumor immunity using mammalian heat shock protein 70 DNA vaccines for cancer immunotherapy. Vaccine. 24:5360-5370.

Shimoda L.A., Manalo D.J., Sham J.S.K., Semenza G.L., and Sylvester J.T. (2001). Partial HIF-1\{alpha\} deficiency impairs pulmonary arterial myocyte electrophysiological responses to hypoxia. Am. J. Physiol. Lung Cell. Mol. Physiol. 281:L202L208.

Sime F., Monge-C C., and Whittembury J. (1975). Age as a cause of chronic mountain sickness (Monge's disease). Int. J. Biometeorol. 19:93-98.

Smith G.C.M., Cary R.B., Lakin N.D., Hann B.C., Teo S.H., Chen D.J., and Jackson, S.P. (1999). Purification and DNA binding properties of the ataxia-telangiectasia gene product ATM. Proc. Natl. Acad. Sci. U.S.A. 96:11134-11139.

Sofowora G., Dishy V., Xie H.G., Imamura H., Nishimi Y., Morales C.R., Morrow J.D., Kim R.B., Stein C.M., and Wood A.J. (2001). In-vivo effects of Glu298Asp endothelial nitric oxide synthase polymorphism. Pharmacogenetics. 11:809814.

Spicuzza L., Casiraghi N., Gamboa A., Keyl C., Schneider A., Mori A., León Velarde F., Di Maria G.U., and Bernardi L. (2004). Sleep-related hypoxaemia and excessive erythrocytosis in Andean high-altitude natives. Eur. Respir. J. 23:41-46.

Storkbaum E., Lambrechts D., and Carmeliet P. (2004). VEGF: once regarded as a specific angiogenic factor, now implicated in neuroprotection. Bioessays. 26:943-954.

Sui G.J., Liu Y.H., Cheng X.S., Anand I.S., Harris E., Harris P., and Heath D. (1988). Subacute infantile mountain sickness. J. Pathol. 155:161-170.

Sun S., Oliver-Pickett C., Ping Y., Micco A.J., Droma T., Zamudio S., Zhuang J., Huang S.Y., McCullough R.G., Cymerman A., and Moore L.G. (1996). Breathing and brain blood flow during sleep in patients with chronic mountain sickness, J. Appl. Physiol. 81:611-618.

Tiret L., Rigat B., Visvikis S., Breda C., Corvol P., Cambien F., and Soubrier F. (1992). Evidence from combined segregation and linkage analysis that a variant of the angiotensin I-converting enzyme (ACE) gene controls plasma ACE levels. Am. J. Hum. Genetics 51:197-205.

Tsianos G., Eleftheriou K.I., Hawe E., Woolrich L., Watt M., Watt I., Peacock A., Montgomery H., and Grant S. (2005). Performance at altitude and angiotensin I-converting enzyme genotype. Eur. J. Appl. Physiol. 93(5-6):630-633.

Vargas E., and Villena, M. (1992). Intercambio gaseoso y relación ventilación perfusión en el mal de montaña crónico. Acta Andina. 41(R34):47-48. 
Vargas E., Villena M., Salinas C., Armando R., Spielvogel H., Téllez W., and Bellido D. (2003). Excessive polycythemia occurs in young high altitude $(3600 \mathrm{~m})$ residents in absence of lung disease. In: Health \& Height: Proceedings of the 5th World Congress on Mountain Medicine and High Altitude Physiology. G. Viscor, A. Ricart, and C. Leal, eds. Universitat de Barcelona, Barcelona; pp. 43-48.

Winslow R.M., and Monge-C C. (1987). Hypoxia, Polycythemia and Chronic Mountain Sickness. John Hopkins University Press, Baltimore, pp 19-30.

Woods D.R., Pollard A.J., Collier D.J., Jamshidi Y., Vassiliou V., Hawe E., Humphries S.E., and Montgomery H.E. (2002). Insertion/deletion polymorphism of the angiotensin I-converting enzyme gene and arterial oxygen saturation at high altitude. Am. J. Respir. Crit. Care Med. 166:362-366.

Wu T.Y., Li W., Li Y., Ge R.-L., Cheng Q., Wang S., Zhao G., Wei L., Jin Y., and Don G. (1998). Epidemiology of chronic mountain sickness: ten years' study in Qinghai-Tibet. In: Progress in Mountain Medicine and High Altitude Physiology. H. Ohno, T. Kobayashi, S. Masuyama, and M. Nakashima, eds. Press Committee of the 3rd World Congress on Mountain
Medicine and High Altitude Physiology, Matsumoto, Japan; pp. 120-125.

Yu A.Y., Shimoda L.A., Iyer N.V., Huso D.L., Sun X., McWilliams R., Beaty T., Sham J.S.K., Wiener C.M., Sylvester J.T., and Semenza G.L. (1999). Impaired physiological responses to chronic hypoxia in mice partially deficient for hypoxia-inducible factor 1\{alpha\}. J. Clin. Invest. 103:691-696.

Zisman L.S. (1998). Inhibiting tissue angiotensin-converting enzyme, a pound of flesh without the blood? Circulation. 98: 2788-2790.

$$
\begin{array}{r}
\text { Address reprint requests to: } \\
\text { Fabiola León-Velarde } \\
\text { Universidad Peruana Cayetano Heredia } \\
\text { Av. Honorio Delgado No. } 430 \\
\text { Lima 31, Peru } \\
\text { E-mail: fleonvelarde@upch.edu.pe }
\end{array}
$$

Received December 10, 2007; accepted in final form March 14, 2008. 